\title{
Urban and regional prosperity in a globalised new economy: an overview
}

\author{
Roger Sugden, Rita Hartung Cheng and \\ G. Richard Meadows*
}

There is currently a popular view that the world is undergoing profound changes in the relationships through which it is organised. In particular, there is widespread talk of a 'globalised' economy, facilitated by and associated with 'new' technologies and practices. There is a further consensus that within this globalised, 'new'economy, regionalisation of some form is important. The aim of this volume is to address these topical issues, presenting perspectives from which they can be analysed and understood, and exploring specific aspects in greater detail. We provide a framework for analysing and understanding current trends, and suggest approaches that highlight appropriate ways forward in the context of opportunities and dangers. In doing so, we discuss specific cases and explore detailed policy possibilities, including the prospect of stimulating change through multinational engagement and debate.

Part I of the volume comprises a chapter by Roger Sugden and James R. Wilson. It has two aims. The first is to provide a general introduction to some of the issues and a reference point for later contributions. It reports a set of questions, topics and themes, what might be considered an introductory agenda. The objective is in part to position subsequent chapters in the broader context from which they were derived. It is also to provide a springboard for further questioning and understanding. The second aim of the chapter is to explore a perspective on concepts that provide the basis for the analysis of urban and regional prosperity in a globalised new economy. The intention is to begin to explore items underlying the initial agenda in a manner that provides an overall perspective. In essence, the focus is on aspects of the conceptualisation of 'urban', 'regional', 'prosperity', 'globalised' and 'new' economy.

Having distinguished between democratic globalisation and elite globalisation, the chapter presents notions of urban and regional prosperity as part of the same process. The idea is of a virtuous circle where 'localities' are feeling their way forward, evolving towards paths along which they can govern themselves. It is argued that the ultimate challenge is to move towards a scenario where all actors in each locality, and in the communities within and across 
localities, participate in the democratic governance of their development. Achieving this would imply that urban and regional prosperity is rooted in the inclusion of each person in a globalised new economy; there would be opportunity and ability for everyone to access and shape the globalisation process, and in this sense to be 'citizens of the world'.

Part II of the volume explores specific issues. Its range is very wide, encompassing deindustrialisation, industrialisation, labour market flexibility, enterprise formation, cartels, concentration and the clustering of economic activity.

In Chapter 2, the prime focus of Keith Cowling and Philip R. Tomlinson is that aspect of a globalisation process accounted for by large Japanese firms, the impact on smaller Japanese firms and thus the consequences for regions within Japan. They discuss the problems of 'hollowing out' using a case study of the machinery sector. Their contribution explores the roots of Japan's present crisis by focusing on the role played by the country's large transnational corporations. These corporations are seen as central actors, controlling a significant proportion of manufacturing. It is their strategic decisions - those decisions that determine the level and location of investment, employment and output - which ultimately shape the development path for Japanese industry.

In recent years, Japan's large transnationals have become engaged in the process of (what Part I of this volume characterises as) elite globalisation, pursuing their own interests at the expense of domestic Japanese industry. Japan's firms have established new (overseas) keiretsu, comprising large Japanese transnational corporations and their core domestic suppliers. Increasingly, these new keiretsu have been used by the large transnationals as substitutes for investment and production in Japan. As a result, smaller Japanese firms have been placed in a weaker bargaining position with their main contractors, who have had increasing access to global supply chains. Consequently, Japan's smaller firms have experienced declining order books and have had to accept lower profit margins. The result has been an unprecedented rise in the number of small-firm bankruptcy cases.

The chapter views the strategic decisions made by Japan's elite corporate hierarchies as being incompatible with the wider Japanese public interest, which is concerned with promoting domestic employment and encouraging regional industrial growth and vitality. This fundamental insight is argued to be crucial for designing appropriate policy responses to arrest Japan's current industrial decline. It is further suggested that the lessons from Japan's experience might show policy-makers elsewhere, in regions concerned with their future industrial development, the effects of globalisation and the problems of hollowing out.

An apparently very different sort of economy is the subject of Chapter 3, the discussion of Mexico by Kaye G. Husbands. Nevertheless, the topic of 
foreign direct investment again figures prominently, and there are parallel concerns about indigenous smaller firms being pushed out of supply chains. Moreover, for both chapters the issue might be characterised as a concern with failures to industrialise appropriately, in the case of Japan because the sort of industrialisation has ultimately resulted in a deindustrialisation, and in the case of Mexico because industrialisation has been at best stunted.

The chapter identifies and contemplates a critical question: does economic growth in the likes of Mexico depend on the viability of indigenous Mexican firms, or does production by foreign firms contribute as much or even more to the Mexican economy? More precisely, its concern is technological change and innovation: is there a reduction in indigenous innovation that critically impairs future growth, when foreign firms supplant indigenous firms under liberalised trade and ownership rules? Husbands reviews wide-ranging literature. She concludes that globalisation might foster the upgrading of technology within particular regions by facilitating freer trade and linkages across trading partners. However, latecomer developers - such as Mexico - can better reap the benefits if they possess local systems of technology development. Moreover, she also points to the desirability of indigenous innovation within localities for areas of the world more widely. It is argued that indigenous innovation in 'developing countries' could have positive spillover to 'developed nations'; for example, firms from the US, Japan and Europe might find that access to very distinct technology processes in, say, Mexico, spurs the development of new products and processes that are not only utilised in Mexico but also in their other markets in different parts of the world. This is illustrated with particular cases, especially the automobile industry, and explored in terms of potential public policy by considering industrial and technology clusters, and the role of education programmes.

Chapter 4 is by Johan Willner and is entitled 'Economic activity, market structure and public policy'. It moves the discussion in different directions, albeit also concentrating on different types of enterprise and discussing technological change. Willner's starting-point is the frequent argument that high wages, a large public sector, unionisation, and job security lead to lower output and employment and that this explains why unemployment in Europe is higher than in the US. However, his overview of recent research throws doubts on this popular 'eurosclerosis' hypothesis. Social insurance and the public infrastructure may in fact have a favourable effect on economic activity. Wage flexibility may have a limited effect on employment. Profit opportunities seem to be of limited importance for explaining entry, as compared to a preference for being self-employed, while access to credit may be essential for both entry and survival.

The chapter includes an oligopoly model with and without free entry and credit rationing. While there may indeed sometimes exist a trade-off between 
desirable objectives such as high wages (and indirectly unionisation and high income taxes) and job security on the one hand, and employment and enterprise formation on the other, the relationship turns out to be more complex than usually believed. Better job security may in fact reduce marginal costs, which increases employment in an oligopoly with a fixed number of firms. Higher wages may even lead to increased enterprise formation and have no negative effect on employment if access to credit is an important barrier to entry. Moreover, public production will then lead to an increase in the number of private firms in a mixed oligopoly, and can also offset possible negative effects of higher job security if there is entry and exit under credit rationing. Overall, the implication of Chapter 4 is that an industrial policy may be counterproductive when, in the name of increased profit opportunities, it excludes large segments of the population from the prosperity that high economic activity is supposed to generate.

The chapter by Stanley Siebert continues with the topic of labour market flexibility, discussing the 'eurosclerosis' hypothesis in further detail. It highlights a conceptualisation of the new economy that emphasises a rise in skilled-labour-using technologies, coupled with increasing global competition. Siebert argues that these factors reduce the demand for unskilled labour in the 'developed world', suggesting a lengthening of the lower tail of the earnings distribution. In other words, increased global competition is said to mean that unskilled workers in, say, the UK, need to earn somewhat less so as to be able to compete in the world market. He argues that, in these circumstances, labour market institutions that prevent a widening of earnings differentials may have more of a displacement effect on unskilled workers. Therefore, the rise of the new economy means urgently investigating two important questions. First, do public policies that cut the bottom off of the earnings distribution - for example, minimum wage laws, encouragement of unionisation - merely push people into the bottom of the income distribution? Second, what weight ought to be placed on movements into and out of the bottom of the earnings distribution?

Siebert's analysis of these questions is empirical, considering data from Western Europe, the US and Japan. His findings indicate that labour regulation strengthening unions and/or imposing good working conditions eliminates 'bad' jobs. Such regulation therefore causes unskilled workers (those without the skills to compete for good jobs) to suffer. His findings also indicate that the reason for the suffering is that the average unemployed person would much rather have a job, even a 'bad' job, than remain on welfare. The chapter contemplates the potential for constructing corporatist institutions that might permit more favourable outcomes. Whilst pessimistic, it considers such possibilities to be important on the basis that freedom of association, like freedom of the press, is part of a democratic society. Trade unions have been in the 
forefront of the fight for democracy in many countries, for example South Africa. Siebert concludes that simply wishing trade unions away is neither possible nor desirable; searching for the happy medium for union power is accordingly a central political issue.

Another change of direction is taken in Chapter 6; the broad subject is large firms and globalisation, an issue that repeatedly arises throughout the volume, but the particular topic addressed by John Connor is antitrust and global cartels. He discusses what might be seen as a dark side to globalisation. More specifically, he explores certain effects of the new economy on collusive international business schemes, and describes the responses of competition-law agencies to the growing threat of global cartels. The chapter points to the resurgence of global cartels that began in the 1980s, refers to a number of cartels discovered and prosecuted since 1995 and pays especial attention to the case of lysine, one of the first and most successful biotechnology industries to emerge since 1945.

Connor sees the nexus between cartel formation and the new economy as perhaps subtle and speculative, but nonetheless real. He describes the emergence of a cartel when Archer Daniels Midland Co. (ADM) entered the lysine market, and presents estimates of the global (overcharge and deadweight) losses to customers. These are compared to the penalties exacted from ADM in a calculation of the deterrence effect. His conclusion is that the crime was not made to pay but that the loss in global net revenues was relatively small. As is typical in such situations, ADM was not punished to the full force of the law. Had it been, the firm's losses would have run into billions. The chapter also points to a tendency towards recidivism, and to diversity amongst global corporations as a cause for concern: when diversified corporations benefit from a cartel in one line of business, they are also likely to participate in a cartel in another line. The lower costs of modern means of transport and communication are identified as factors facilitating new economy cartels, but also as responsible for increasing convergence amongst national jurisdictions with respect to the content and execution of competition laws. Connor concludes with a particular warning for regional economies looking to base their success on clusters of activity in particular sectors; the benefits from clustering might vanish if antitrust rules are violated.

This last point is particularly pertinent as regional concentration in particular sectors of economic activity, 'clustering' of one form or another, is a key concern in many debates on economic development at the current time. It is also the focus of the next three chapters of the volume.

For James Peoples, the globalisation of business activity makes it imperative that firms adopt strategies that enhance their competitive advantage. $\mathrm{He}$ considers one possible strategy to be regional concentration of business operations, and presents evidence to show that many industries in the US are 
geographically concentrated; for example, he indicates that more than 40 per cent of US aircraft are manufactured in Los Angeles, Seattle or Fort Worth.

Chapter 7 argues that regional concentration may enhance the productivity of businesses. It is hypothesised that, in part, the explanation for productivity improvement might be that locating operations at a few metropolitan areas facilitates the development of centres of expertise. It is further argued that the competitive advantage associated with high productivity also contributes to regional prosperity by lowering employees' risk of job loss, and by providing these employees with high paying jobs. In contrast, it is suggested that the potential for improved industrial performance might not present firms with a sufficiently significant advantage to warrant concentrating their operations; firms might favour geographical dispersion, to avoid high transportation costs and to limit their reliance on any one local labour market. Peoples utilises worker and industry information on manufacturing industries to examine the issues. He concludes that the findings indicate that industry productivity levels are highest when the four major production localities employ 40 per cent of the industry workforce. Further analysis is also said to reveal greater educational attainment by workers employed in these centres of activity; the argument is that local employment of a highly educated workforce helps explain high productivity at such locations. The chapter lends support to municipalities' efforts to help their regions become centres of expertise, and indicates that efforts to develop such centres are well served by municipalities investing in their institutions of higher education.

The topic of Chapter 8, by Stuart O. Schweitzer and Marco R. Di Tommaso, is clusters in new high-technology sectors, including biotechnology. They too have an interest in institutions of higher education, asking whether universities, amongst other things, are important in the clustering process.

The chapter begins with some considerations regarding geographical agglomeration over time, drawing out concerns in the 'old economy' and pointing towards what is additionally relevant about the 'new economy'. It identifies two themes explaining clustering by firms. The first refers to specific factors that draw particular firms to certain localities. In the old economy these place-specific geographic endowments included ease of transportation, the pull of raw materials and the lure of product markets. It is argued that in the new economy the situation is somewhat different; changes in information and communication technologies suggest that transportation costs have been largely eliminated as an important consideration, and 'commerce' is now more a case of transmission of digitised information over the Internet than of exchanges of physical outputs. The second theme emphasises synergies among firms, the advantages of physical proximity. These might include access to a local market for skilled labour, or to specific technical or market knowledge. The authors suggest that in modern, high-technology industries, 
experience in the likes of Silicon Valley implies that physical proximity to other firms and in particular to other similar, specialised and complementary firms can offer great benefits. At issue are not only the passive exploitation of other firms' presence, but also the active development of strategic relationships.

The role of proximity is pursued in a discussion of the life-cycle of biotechnology firms. This leads to the hypothesis that universities are significant location determinants, because they are sources of knowledge and of scientifically skilled personnel. The emphasis of Schweitzer and Di Tommaso is on research-oriented universities, not educational institutions in general. They conclude that if their depiction of the life-cycle is accurate, and is consistent with the model by which firms cluster together in proximity to research universities, an important policy instrument is clearly suggested: the creation of a network of strong research-oriented universities that are structured so as both to support high-technology firms, and even to promote spin-offs.

In Chapter 9, Marco Bellandi also discusses clustering in the new economy. The motto of Marshall's Industry and Trade (1919) is: 'the many in the one, the one in the many'. For Bellandi, it may also be read: 'the global in the local, the local in the global'; global tendencies enter into the life of localities, but any global tendencies emerge as the result of the peculiar manifestations characterising different local contexts. ${ }^{1}$ Whilst arguing that Marshall considered this particular ramification, Bellandi also sees it as more evident nowadays, with the diffusion of new information and communication technologies, the widespread activity of private and public transnational organisations, the reemergence of local and regional contexts of social and economic activity, and innovation.

From such inspiration, Chapter 9 focuses on four concerns. First, it reviews some general points about clustering by considering the experiences of Italian industrial districts, commenting especially on large corporations, external economies, and small-to-medium specialised firms as engines of growth. Second, attention turns to the wider role of clusters in economic development; Bellandi considers the concept of a cluster, its association with territories explicitly returning the analysis to the idea of localities introduced in Chapter 1 - and the contexts in which clusters emerge and prosper. Third, the chapter contemplates the significance of the new economy for the nature and impact of clustering processes. Fourth, the specific case of South-eastern Wisconsin is discussed, raising queries relevant to many parts of the world about the desirability of clusters as a route to economic success. Concern with this particular case also provides an effective bridge into Part III of the volume.

One aim of Part III is to consider a specific case in further detail, moreover the case that was at the heart of initial discussions motivating the request for contributions to this volume. Another is to draw together aspects of the 
relevance and applicability of the analysis in Parts I and II: whereas Part I provides anchor points for subsequent chapters, one intention in Part III is to present material that draws on arguments in earlier chapters to discuss experiences and possibilities in a particular case, seeing this as illustrative of more widely applicable points about urban and regional prosperity in a globalised new economy. A third aim of Part III is to reflect on the processes underlying (amongst other things) the publication of this volume.

Throughout the previous chapters, the volume refers to examples from areas in various countries. Included in this, there are periodic, brief references to the state of Wisconsin (US). That case is considered in greater depth in Part III, which accordingly opens with a chapter by Donald A. Nichols providing a detailed discussion of the situation facing a traditional manufacturing area looking to prosper in the modern, global economy. This outlines the current position in the particular case and identifies what its author sees as especially crucial issues at this point in time. The analysis is more widely relevant not least because the people of Wisconsin are facing problems that are shared by many other regions throughout the world as they embark on a new century of change.

Nichols sketches how the new economy and globalisation have affected manufacturing, and notes the challenges posed for the future. It is argued that the first step in recognising these challenges is to understand if there really is such a thing as a 'new economy', and if so, whether it has openings into which a set of 'old economy' industries can be incorporated. Specifically, can an area like Wisconsin use its traditional industries as stepping-stones to join the new economy and enjoy its benefits? Nichols concludes that it can, because in many instances it is the old economy that provides the market for new economy products. The chapter concentrates most of its attention on the large and volatile machinery industry, which provides over half of Wisconsin's exports and which is the sector most sensitive to export fluctuations and import competition. This industry is concentrated in the South-eastern part of the state. Nichols describes what South-eastern Wisconsin might be like if it remains the hub of some old economy machinery industries, but operates in the new economy mode of entrepreneurial venture capitalism while developing new technologies for its traditional industries.

The attention on South-eastern Wisconsin is maintained in Chapter 11. Mark A. Mone reflects on attempts by the University of Wisconsin-Milwaukee to enhance economic development in the area over the period 1998-2002. He describes the context for these efforts, looking at the involvement of the university in a variety of initiatives, and reports on specific outcomes; the chapter includes a detailed report on South-eastern Wisconsin as an Appendix, written by Nancy L. Zimpher, Mark A. Mone, Sammis White, Timothy R. Sheehy and Kris Piwek. The chapter also offers personal conclusions and suggestions about the process of university involvement. 
Varied opinions on the role of a university are considered and the lack of a universally agreed approach is noted. Mone argues that a sense of social responsibility and of self-preservation ought to impel universities to engage in issues of local economic development. He discusses the need for different constituencies to be suitably represented, and the implications of absence. The chapter also considers the reactions to a university attempting to take a lead and concerns about leadership more generally. Alluding to the commonly held view in management literature that different skills are required to launch as compared to expand a business, it is suggested that the start of a local economic development process that brings together many and varied constituencies might need the skills of a visionary champion. This would be someone capable of marshalling the different constituents, gaining commitment to overarching themes and goals, and having the connections to bring the necessary resources to bear. To then sustain these efforts, other skills are necessary, those that would ensure that an appropriate infrastructure is resourced and effective. There are potential problems of turf wars as well as of defensive attitudes to change and alleged threats, for example from those already employed in positions of economic development responsibility. $\mathrm{He}$ argues that key stakeholders need conviction in the process, and there must be practical forms of collaboration. As for a university in particular, it is concluded that any academic institution involved in local economic development has a significant responsibility. The university must feature a sustained and resourced commitment, a concomitant restructuring of its activities, and understanding and acceptance amongst its academics and administrative staff.

The concluding chapter also provides, as an Appendix, a report that discusses economic prosperity in South-eastern Wisconsin. This report is authored collectively by participants at the L'institute-Milwaukee Workshop on 'Urban and regional prosperity in a globalised economy'. It is entitled 'International perspectives on South-eastern Wisconsin's economic development' and, as detailed in Chapter 12, was first-drafted and debated by participants during the course of the workshop. The report implicitly draws on material presented in earlier chapters of this volume and, like Chapters 10 and 11 , is relevant to wider localities.

Moreover, Chapter 12 provides a personal reflection on the process that led to the publication of this volume and the writing of the report, both of which are part of a deliberate attempt to involve international expertise in debates about economic development in particular regions. They are aspects of a process of stimulating change through multinational engagement and debate. Such multinationalism is itself a response to the challenges that regions currently face. What might be advocated is that a like-minded process be introduced in similar circumstances elsewhere, as part of a strategy for ensuring 
urban and regional prosperity in a globalised new economy. The chapter attempts to draw lessons from experience that might aid future initiatives.

More specifically, in Chapter 12, J. Robert Branston, Roger Sugden and James R. Wilson explore the aims of the L'institute-Milwaukee Workshop as initially conceived, and ask whether these aims have been realised. The chapter seeks to identify problems that were encountered, and make tentative suggestions as to how these might be overcome. The motivation for such an analysis lies in an ongoing concern to become part of the process of economic development in particular localities. In this regard, the current volume is not an end-result. Crucially, then, the chapter concludes with thoughts on how and where the process might develop from here. Amongst the lessons to be learned, special focus is given to the 'insider'/'outsider' issue; that it is not for outsiders to come into town for a couple of weeks and pretend to understand local conditions and desires, let alone attempt to start telling local people how to run their economy. It is emphasised that, if development is to be based on the aims, objectives and actions of the people of a locality, and if those outside the locality might be able to contribute ideas and suggestions for locals to act upon as they decide, then both insiders and outsiders need to be aware of each other's roles, respectful of each other, and willing to learn together as the process unfolds. This is a point that is also relevant to the activities of various international organisations, for example the World Bank, and successfully taking it into account is a prerequisite if economies are to benefit from multinational interaction. One of the motivations for this volume is to bring such benefits closer to realisation.

\section{NOTES}

* This contribution to the volume is presented as a form of abstract. It draws freely from correspondence with authors and from the words of each chapter, using those words without quotation marks (the inclusion of which might have made the overview less easy to read). The aim is to assist the reader by providing a sort of summary. In no circumstances ought this contribution to be quoted in its own right; quotation ought always to be from the specific chapters that follow. It is of course the case that any misrepresentations and errors in this overview are the sole responsibility of its authors.

1. This is a point emphasised by Bellandi in his presentation at the Second L'institute-Milwaukee Workshop.

\section{REFERENCE}

Marshall, A. (1919), Industry and Trade, London: Macmillan. 
Roger Sugden, Rita Hartung Cheng, and G. Richard Meadows - 9781781951217 Downloaded from PubFactory at 04/26/2023 01:05: 05PM via free access 